\title{
THE RENAISSANCE OF FAIRNESS IN GROUND RISK ALLOCATION - THE NEW ITA/FIDIC EMERALD BOOK
}

\author{
A. E. Dix \\ Engineering Department, Visiting Professor of Tokyo City University, \\ Tokyo, Japan
}

\begin{abstract}
Unfair contracting practices are a major contributor to the high cost, failed schedules, bankrupted Contractors and other abominations afflicting major subsurface projects in many countries. The new Emerald Book is an ITA/FIDIC joint initiative to create a fairer contractual framework for the construction of underground works and heralds an international recognition of the benefits of carefully apportioning ground conditions risk.
\end{abstract}

Inappropriate risk allocation contributes to the cost, schedule uncertainty, business risk and complexity of underground infrastructure delivery.

In recent decades ill-informed allied professionals have wrongly guided Employers to specify irresponsible contractual terms that entirely place ground condition risk (sovereign risk) with the Contractors and then invite the market to enter a fierce commercial battle in which the lowest bidding Contractor assumes the sovereign's ground risk. Financiers are advantaged by such risk apportionment but rarely is this motivation for such practices acknowledged or discussed.

Under the new Emerald Book, FIDIC arrangements commercial tension is directed to the price for construction and associated works for the execution of the excavation and lining works including design and construction methods and the reaction of the ground to such methods. The Geotechnical Baseline Report sets out the allocation of the risk between the parties for such subsurface physical conditions.

Under the new FIDIC/ITA Emerald Book arrangements the Contractor is expected to perform in accordance with its bid and is only compensated for the conditions encountered. For the Employer this means that they can rely upon the Contractor to perform as warranted under the Contract - demanding the competence, skill and expertise required to undertake the anticipated task. For the Contractor it means that where the encountered conditions and reaction of the ground is not as warranted by the Employer, there is a mechanism to adjust the terms of the Contract to compensate for the consequences of unanticipated conditions.

The attraction of this new FIDIC/ITA Emerald Book Contract framework is that for the most part it draws upon the well-known normal FIDIC forms of contracting providing reassurance to Employers, Contractors and Banks that the allocation of 
risks, mechanisms for dispute and conduct of Contract management are sound, reliable and internationally understood.

Innovative features of the new Emerald Book include a contractual mechanism to extend or shorten the time for completion, adjustments to remuneration and a focus on the expertise of the Contractor. Importantly these innovations are linked to Geotechnical Baseline Reports and therefore the rock. In this way rock beats paper because remuneration is based upon fact and not maneuvering for commercial variations and other elaborate desperate mechanisms.

Keywords: Contracts, Geotechnical, Risk, Underground, GBR and Costs.

Cite this Article: A. E. Dix, The Renaissance of Fairness in Ground Risk Allocation The New ITA/FIDIC Emerald Book. International Journal of Civil Engineering and Technology 11(1), 2020, 43-52.

http://www.iaeme.com/IJCIET/issues.asp?JType=IJCIET\&VType=11\&IType=1

\section{INTRODUCTION}

The new FIDIC[1]/ITA[2] underground works standard Contract of 2019 heralds an international change in direction of apportioning risk by rightly recognising the role of ground conditions in formulating the reward for Contractors for effort and the demand by Employers for Contractors to perform.

The apportionment of ground risk in a technical context within a structured contractual risk sharing legal framework is an international step change in ground risk apportionment. This new Contract is known as the Emerald Book, 2019 Ed. It is based upon FIDIC's highly successful Conditions of Contract for Plant and Design-Build, FIDIC's Yellow Book.

The ITA, Contractual Practices Group, chaired by the author, produced "The ITA Contractual Framework Checklist for Subsurface Construction Contracts" of April 2011.[3] This document (now in review for 2nd Edition), was the first articulation of the special subjects requiring consideration in an underground works contract.

The ITA conducted a world survey of the performance of subsurface construction projects and found that there was a correlation between 'on time' and 'on budget' projects and the use of sophisticated risk apportionment methodologies, technically competent Employers and Contractors. The most pertinent example came from Switzerland where the Swiss Tunnelling Contracts tended to result in a greater degree of certainty of quality, cost and timeframe outputs.

A detailed analysis of the Swiss suite of contracts also revealed that they were tailored to a European context and therefore, despite being the most sophisticated contracts identified, were not considered readily transferrable to becoming a default international model, although their merit in sophisticated and experienced subsurface construction countries is undeniable.

The ITA then set about a process of identifying key global 'off the shelf' standard form Contracts that might become the base for a new global underground works template.

Several international organisations were approached to collaborate with ITA to formulate a bespoke global underground works contract - FIDIC rose to the challenge and a joint task force was established. After more than 5 years of collaboration between experts from more than 40 countries the first edition of the joint FIDIC / ITA conditions of contract for underground works was released in May 2019 as the Emerald Book, 2019 Ed. It is anticipated that the Emerald Book will be the first of many underground works specific forms of contract. ITA's objective is to develop a global culture for fair risk apportionment in underground works. 
The apportionment of ground risk in a technical context within a structured contractual risk sharing legal framework is a step change in ground risk apportionment. The Emerald Book is based upon FIDIC's highly successful conditions of contract for plant and designbuild (FIDIC's Yellow Book) [4].

Under the new Emerald Book, FIDIC arrangements, commercial tension is directed to the price for construction and associated works for the execution of the excavation and lining works including design and construction methods and the reaction of the ground to such methods. The geotechnical baseline report (GBR) sets out the allocation of the risk between the parties for such subsurface physical conditions.

The Employer has the ability within the GBR to throttle the level of ground risk by defining the ground conditions for the purposes of obtaining a bid. The Employer is not required to draft a 'correct' GBR - the GBR merely serves as the measure by which the Works and their rate of construction by the Contractor will be linked to the agreed price. The specific wording of the GBR is the way in which the risk of ground conditions variability is apportioned. The GBR is the point of reference for adjusting the Contract remuneration and timing. It is not, and never was intended to be, a dissertation on the underground conditions in an academic or theoretical sense. Sometimes boffins get confused about the GBR - it is not the trigger for infinite ground investigation - it is just an articulation of a base line so that performance and reward can be measured.

The GBR formulation will directly influence the allocation of risk. An overly cautious GBR may result in higher bid prices, whereas an overly simplified GBR may excuse a Contractor from otherwise foreseeable risks.

Under the provisions of the Emerald Book arrangements the Contractor is expected to perform in accordance with its bid and is rewarded or punished by referencing the contracted technical conditions. For the Employer this means that they can rely upon the Contractor to perform as warranted under the contract - demanding the competence, skill and expertise required to undertake the anticipated task. For the Contractor it means that where the encountered conditions and reaction of the ground is not as warranted by the Employer, there is a mechanism to adjust the terms of the contract to compensate them for the unanticipated conditions.

The attraction of this new FIDIC - ITA Emerald Book contract framework is that for the most part it draws upon the well-known normal FIDIC forms of contracting providing reassurance to Employers, Contractors and banks that the allocation of risks, mechanisms for dispute and conduct of contract management are sound, reliable and internationally understood.

Innovative features of the new Emerald Book include a contractual mechanism to extend or shorten the time for completion, adjustments to remuneration and a focus on the expertise of the Contractor. Importantly these innovations are linked to the GBR and therefore the rock. In this way "rock beats paper" because remuneration is based upon fact and not maneuvering for variations and other elaborate legal mechanisms.

It is expected that the Emerald Book will provide thought leadership to Employers, lawyers, bankers and insurers about alternative means of appropriately apportioning risk in large underground works projects. While the Emerald Book is definitely not applicable to delivering all projects, it provides thought leadership that will contribute to equitable apportionment of risk between the State and Contractors and thereby protect all parties from windfall losses and gains driven by unexpected ground conditions.

As Sir Harold Harding has said [5]:

"The only bore hole that can be relied upon to describe the ground conditions precisely would be one the length of the tunnel and several feet larger in diameter." 
Let us hope that the Emerald Book assists the world to responsibly deliver the underground infrastructure it so desperately needs without destroying the construction industry upon which the projects rely.

The author laments that in countries such as Australia the results of unfair risk apportionment have decreased the number of local contracting companies, capable and willing to assume subsurface risks, despite an Australian subsurface construction 'boom'. The consequences on cost, delivery times and quality of such practices remains to be seen, but it is almost certain unfair ground risk apportionment will adversely impact the outcomes. Hopefully the Emerald Book will encourage parties to reembrace the concepts of fairness in contracting.

\section{KEY FEATURES OF THE EMERALD BOOK}

\subsection{Underground Works}

As noted in the forward to the Emerald Book 2019 Ed. [6]:

"Compared to other works, underground works are predominately characterised by three unique features:

- The method of excavation and ground support are major factors for the successful realization of the project, and therefore part of the Works;

- Physical access to the Works is often limited to just a few locations or even a single location, which places serious constraints on construction logistics and the environment; and

- The land beneath which the Works are to be constructed, typically belongs to a number of parties.

Further there are two other important features that are not unique to underground works, but which are characteristic of all such works:

- They require extensive investment in Contractor's equipment; and

- Underground excavation and lining works are very time-consuming."

The Emerald Book notes that it is essential that the employer gives careful consideration to all of these key features of underground works projects during the preparation of tender documentation because the successful completion of the works and the ability of a tenderer to rightly price the works is a direct function of these unique and fundamental features of underground works projects.

\subsection{The Priority of Contractual Documents}

To understand how the Emerald Book Contract works, demands knowledge of what lawyer's call, 'priority of documents'. Under the Contract the documents are ordered in decreasing 'priority'. The Contract agreement itself has the highest priority and the lowest priority is accorded to documents like the Geotechnical Data Report (GDR), the Risk Register and even the Contract Risk Management Plan.

The Contract data, the Completion Schedule and the Schedule of Baselines are a higher priority than the GBR. And the GBR has a higher priority than even the Employers Requirements, General Conditions, Contractors Proposal and even Joint Venture undertakings (Clause 1.5).

It is this priority of requirements that drives certainty in an Emerald Book project. Uncertainty of requirements is cured by the priority of the document in which they appear. 
The Completion Schedule and the Schedule of Baselines provide the trigger for intervention by the Employer's Engineer. This is how risk is fairly apportioned. The Contractor is expected to do the job as they tendered in accordance with the agreed schedule this is the priority under the Contract. If conditions are not as expected and loss is incurred then, and only then, is the Employer liable. This Contract focuses on the engineering, the excavation and the lining. The Contract is intentionally directed away from lawyers except for its proper administration in accordance with law which includes the professional conduct of the major actors under the Contract - especially the Engineer.

\subsection{The Engineer}

As foreshadowed above the Engineer plays a central role in administration of the Emerald Book conditions. The Engineer is deemed to act for the Employer. (Clause 3.2.1) However, the Engineer must, at all times, act professionally and in relation to some special duties must:

'... act neutrally between the Parties and shall not be deemed to act for the Employer'. (Clause 3.7)

The duty to act fairly (Clause 3.7.2) in relation to Claims is overarching and implies a range of administrative and quasi-judicial characteristics. This overarching requirement of fairness underpins the success of an Emerald Book underground works project. As would be expected there is a mechanism to challenge an Engineer's decision (Clause 21.4) which results in the Dispute Avoidance Board ("DAB") undertaking a decision review and, failing compliance with the DAB's decision an arbitration mechanism is provided (Clause 21.6). The Engineer is at the heart of the administration of an Emerald Book project.

\subsection{The Employers Requirements}

The Employers requirements are included as part of the Contract and describe the purposes for which the works are intended and specified the Contractors key personnel and any special equipment, project scope preliminary design carried out by or on behalf of the Employer (Employer's Reference Design) and design or other performance technical and evaluation criteria for the Works. It is essential to recognise that these requirements are subordinate to the Geotechnical Baseline Report (Clause 1.1.39).

This means that if the ground conditions are not as expected or are as expected but do not accommodate the Employers requirements, a Notice must be issued to the Engineer for clarification (Clause 1.5). This highlights the priority given to the GBR and how it drives behavior of parties under the Contract.

\subsection{The Geotechnical Baseline Report}

The Geotechnical Baseline Report ("GBR") is defined within the Emerald Book as (Clause 1.1.51):

"The report entitled Geotechnical Baseline Report as included in the Contract that describes the subsurface physical conditions to serve as the basis for the execution of the Excavation and Lining Works, including design and construction methods, and the reaction of the ground to such methods. The GBR sets out the allocation of the risk between the parties for such subsurface physical conditions."

It is essential to understand that legally the GBR is not a statement of truth about the actual rock conditions. The GBR describes the basis for the execution of the excavations and lining works, but, it does not warrant that it is correct. The Emerald Book Contract provides the mechanism for what occurs commercially, if it is correct, and also what occurs and how 
time and cost are adjusted if it is not correct. This is at the heart of the Emerald Book risk apportionment model.

Of course, it will usually be better if the GBR closely describes the basis for the execution of the excavations and lining works because in such cases the cost and schedule bid will more likely match the project outcome. However, the fundamental point is, if the GBR is wrong there is a pre-agreed mechanism to adjust the price and schedule.

To balance the GBR a "Geotechnical Data Report", the GDR (Clause 1.1.52), is also included in the Contract and it contains the geological geotechnical and hydrogeological data deemed to be in the employers' possession at the Base Date.

The Base Date (Clause 1.1.4) is a contractually defined term which means the date 28 days before the latest date for submission of the Tender.

When viewed in combination these provisions allow an Employer to go to market and engage bidders with a high degree of commercial tension and allow bidders to aggressively bid based on a common and agreed base case for the underground conditions.

Utilising this contractual framework, the mechanism for payment and time can be adjusted if and when unexpected conditions are encountered. By entering into a Contract with the prospect and mechanism for dealing with differing conditions agreed in advance the risks are more fairly allocated.

If the Contractor fails to deal with the anticipated ground conditions appropriately, they will be punished commercially. If the ground conditions are not as expected the time and remuneration can be adjusted using mechanisms and even rates agreed in advance. To some considerable extent this removes the gambling component of pricing the ground risk and encourages Contractors to focus on substantive issues such as expertise, excavation, mining and support works, design and construction methods.

Of course, there is still a place for the legal team - but the focus shifts from exploring exotic means of extracting money from an Employer (or defending such actions) to examining and evidencing actual conditions encountered and how the project responds to them within the context of a highly regulated Emerald Book disputes mechanism.

Importantly the Emerald Book also deals with lengthening and shortening the project duration as a function of ground conditions. This is a very powerful mechanism from within the Contract - especially so because these projects can span many years, even decades.

\subsection{Time for Completion of Underground Works}

The Emerald Book specifies the Time for Completion.

The Emerald Book contemplates the Time for Completion concept being divisible into sections of a project or even milestones and as part of the Contractor's proposal. The "Completion Schedule" takes on a special meaning (Clause 1.1.8). The Completion Schedule is included in the Contract and states the Time for Completion for permanent and temporary Works, any part of the works defined in the Contract, any milestones (completion of excavation and completion of lining are deemed milestones (Clause 1.1.63)) and setting out the logical sequential links between each Time for Completion (Clause 1.1.8) are not negotiable Contract deliverables.

What is different is that the Time for Completion is specified as a number of days to which is added any extensions of time that the Contractor is entitled to. Grounds for extensions of time include:

- A change in the Employer's requirements (a variation) 
- Exceptionally adverse climatic conditions (unforeseeable having regards to the climatic data made available by the employer and/or climatic data published in the country for that geographic location)

- Unforeseeable shortages in personnel or goods caused by epidemic or government action

- Any delay impediment or prevention caused by or attributable to the employer the employer's personnel or the employer's other Contractors on the site (Clause 8.5)

- The results of measurement of the excavation and lining works (Clause 13.8)

If the Contractor has diligently followed the procedures laid down by the relevant legally constituted public authorities or private utility entities in the country and those authorities or entities delay or disrupt the Contractor's work and the delay or disruption was foreseeable then this delay or disruption is considered grounds for extension of Time for Completion (Clause 8.6).

On the other hand if actual progress is too slow to complete the Works, a section, to meet a Milestone or if progress has fallen behind the program then the Engineer may instruct the Contractor to submit a revised program describing revised methods the Contractor proposes to expediate progress and complete the Works Section or meet any Milestones within the Time for Completion. These proposals are entirely at the Contractors expense and may even be the subject of a claim by the Employer for additional costs incurred (Clause 8.7).

In this way the Contractor is at risk for failing to meet the agreed contractual timelines for project delivery due to its failure to meet its promises under the Contract but the Employer is responsible for consequences arising from ground conditions outside the GBR or other circumstances in the Employer's control or departing unforeseeably from the site data provided under the Contract.

\subsection{Use of the Geotechnical Baseline Report}

Under the Contract the Contractor is deemed to have based their Tender and their proposal for excavation and lining works on the subsurface physical conditions and ground reactions described in the GBR. Even if there are other documents and the data made available to the Contractor during Tender that suggest otherwise - the GBR is paramount (Clause 4.10.2). The Contractor is also deemed as far as 'practicable' to have obtained all necessary information as to risks, contingencies and other circumstances which may influence or affect the Tender or Works and to have as far as 'practicable' examined the site, its surroundings and other available information on (Clause 4.10.1):

- Form and nature of site and adjacent structures

- Hydrological and climatic conditions

- Extent and nature of the work and goods necessary for the execution of the works

- The laws, procedures and labor practices of the country

- The Contractor's requirements for access, accommodation, facilities, personnel, power, transport, water and any other utilities and services

\subsection{Price}

Under the Emerald Book there is an Accepted Contract Amount for the Works. That amount is deemed to cover all of the Contractors obligations under the Contract and all things necessary for the proper execution of Works in accordance with the Contract (Clause 4.11). 
Project delays and additional costs actually incurred are recoverable as a result of subsurface physical conditions actually encountered that are outside the limits described in the GBR (Clause 13.8).

There is a strict mechanism for giving the Engineer notice of such unforeseeable conditions which have or are likely to have an adverse effect on progress or cost.

Notice must:

- Be given as soon as practicable and in good time to allow the Engineer opportunity to in spect and investigate the physical conditions properly and before they are disturbed

- Describe the physical conditions, so that they can be inspected and/or investigated promptly by the Engineer

- Set out the reasons why the Contractor considers the physical conditions to be Unforeseeable

- Describe how the physical conditions will adversely affect progress and/or increase the cost of the execution of the Works

Ideally the Notice should include proposals for measures to be taken to further investigate or mitigate such physical conditions (Clause 4.12.1).

\subsection{Engineers Duties}

The Emerald Book imposes strict requirements mandating the Engineer:

'inspect and investigate the physical conditions ... immediately ...'

all within a period of days as agreed with the Contractor. At the same time and during this period the Contractor is required to continue execution of the Works using such proper and reasonable measures as are appropriate for the physical conditions while also enabling the Engineer to inspect and investigate them.

\subsection{Unforeseen Physical Conditions Not Described in the GRB}

At the heart of the Emerald Book risk apportionment is the delay and cost provision which clearly states that if the Contractor encounters physical conditions that will have an adverse effect on the progress or increase the cost of the execution of the Works and they are not described in the GBR (Clause 4.12) then:

'If and to the extent that the Contractor suffers delay and/or incurs Cost due to these physical conditions [those having an adverse effect on progress and/or increased the cost of the execution of the Works] ... the Contractor shall be entitled ... [to] payment of such Cost.'

\subsection{Time Related Charges}

Underground works projects have especially high costs of investment in areas such as equipment and large depreciation costs, interest and overheads. This means, that an atypically high proportion of the cost to the Contractor is time related while the remainder of the cost depends on the volume or quantity of the performed works.

As a result, the Emerald Book specifically provides adjustment of Time for Completion due to the difference between the contractually agreed and the encountered subsurface physical conditions. This means a departure to the conditions encountered in the GBR may also lead to an adjustment of the Contractors remuneration for time related charges. The Bill of Quantities for Excavation and Lining Works (Clause 13.8.2) should distinguish between time related rate items, quantity related items and fixed rate items for the performance of the Works (Clause 13.8.3). The Time for Completion can be shortened or extended, and the financial consequences of such changes will depend upon the reason for the change. In all 
cases the variation in Contract Price is adjusted by having regard to measurements, appropriate rates and prices for items in the Bill of Quantities (Clause 13.8.4).

\subsection{Payment for Excavation and Lining Works}

Normally only the excavation and lining works are subject to measurement and the accepted Contract amount is deemed to cover all other underground works and all things necessary for the proper execution and completion of the Contract.

Furthermore, if, and only to the extent that the Contractor suffers delay, and/or incurs costs as a result of subsurface physical conditions actually encountered that are outside the limits described in the GBR those costs and delay are also dealt with under the Contracts unforeseeable physical conditions provisions. Practically this means that once such physical conditions are encountered the Contractor must give notice to the Engineer, and a timely investigation be conducted and if factually proven an award for payment to the Contractor made.

\subsection{Process for Award Payment}

Either party can claim under the Emerald Book. Importantly there are strict timelines for making claims. This means that the common practice of 'keeping your powder dry' by not making claims as they arise has not place under the Emerald Book. For example, the claiming party must make their claim to the Engineer as soon as practicable, but in any case, not later than 28 days after becoming aware (or should have been aware) of the event or circumstances causing the claim (Clause 20.2.1). If they fail to make the claim within time they are deemed to be not entitled to any additional payment. However, if the Engineer does not take objection to an out of time claim within 14 days after receiving the Notice, then the Notice is considered valid even though it is out of time. In this way the dynamics of Notice and Claims is maintained while keeping the focus on the engineering events which underly the Claims (Clause 20.2.2).

There is also a mechanism with strict time limits for providing the full details of the Claim. In the case of excavation and lining Works it must be to the rates and prices in the Bill of Quantities. Contemporary records are an essential component in substantiating a Claim and have special weight in determining the Claim (Clause 20.2.3).

\section{CONCLUSIONS}

The Emerald Book marks a critical step change in global recognition of the importance of ground conditions when apportioning risk in subsurface construction projects. The collaborative multinational effort of FIDIC/ITA provides a transparent example of how ground risks can be fairly and responsibly managed. This mechanism provides a framework in which Contractors are rewarded for effort and punished for incompetence and Employers gain the benefit of transparent risk sharing including reduced cost.

The global construction industry is highly stressed, in part due to the adoption of illinformed and unfair practices in the allocation of ground risk. Countries such as Australia are testament to the consequences of unfair risk allocation contributing to local contracting capacity having been severely impacted in the face of lawful but unfair ground risk allocation in contractual practices by Clients.

In projects such as Snowy 2.0 in Australia there is evidence that more appropriate risk sharing is finding its way into large underground infrastructure projects even before the release of the Emerald book in May 2019. The world is likely in the process of rediscovering the value of fair contracting practices and the Emerald Book is likely part of that renaissance process. 
ITA's continued objective is to cultivate a global appetite and culture for fair risk apportionment in underground works.

A recalibration of focus on the substantive engineering and technical resolution of disputes is a healthy sign that the resources of a project will be directed to achieving the desired infrastructure outcome. The big winners of fairer Contracts will be our societies because it will be easier to maintain competition in a market focused on engineering and not gamesmanship and gambling about ground conditions. The use of global Contracts may also provide some comfort to foreign lenders and Contractors considering doing business in foreign countries. It is expected that ITA will collaborate with other global Contract providers to provide new examples of fair risk allocation for other procurement strategies serving the global underground construction demand.

\section{ACKNOWLEDGEMENTS}

Professor Dix initiated and championed the FIDIC/ITA Emerald Book collaboration and was a joint Tutor and peer reviewer of the Emerald Book. Special acknowledgement also to the founders of this project in 2012 being Arnold Dix ITA WG3 Animateur, Enrico Vink of FIDIC and Martin Smith ITA WG3 Secretary. Special acknowledgment is also made of FIDIC-ITA Task Group 10 under the Chairmanship of Matthias Neuenschwander whom delivered the final Emerald Book 2019 Ed along with peer review and special GBR expertise of Randall Essex, ITA.

\section{REFERENCES}

[1] FIDIC, the International Federation of Consulting Engineers, (the Fédération Internationale des Ingénieurs-Conseils) is the global representative body for national associations of consulting engineers.

[2] Founded in 1974, the International Tunnelling and Underground Space Association (ITA) aims to encourage the use of the subsurface for the benefit of public, environment and sustainable development and to promote advances in planning, design, construction, maintenance and safety of tunnels and underground space. ITA is supported by 75 Member Nations and 310 Affiliate Members.

[3] "The ITA Contractual Framework Checklist for Subsurface Construction Contracts", April 2011, ISBN 978-2-9700634-7-9.

[4] The Yellow Book in turn was published by FIDIC as an update of the FIDIC 1999 Conditions of Contract for Plant and Design-Build (Yellow Book), First Edition.

[5] Sir Harold Harding DSc, BSc (Eng), FEng, Presidential Address, Proceedings of the Institution of Civil Engineers, November 1963.

[6] FIDIC., Opening Notes - Conditions for Contract for Underground Works - The Emerald Book 2019 Ed. 